\title{
Sistem Informasi Pendaftaran Anggota Baru Pada Palang Merah Indonesia (PMI) Jakarta
}

\author{
Endah Wiji Lestari ${ }^{1}$, Nanda Yustie Mirchandini ${ }^{2}$ \\ ${ }^{1}$ Universitas Bina Sarana Informatika \\ e-mail: endah.ewl@bsi.ac.id \\ ${ }^{2}$ Universitas Bina Sarana Informatika \\ e-mail: nandayustie21@gmail.com
}

Cara Sitasi: Lestari, E. W. (2019). Sistem Informasi Pendaftaran Anggota Baru Pada Palang Merah Indonesia (PMI) Jakarta. Paradigma - Jurnal Komputer dan Informatika, 21(2), 173-178. doi:10.31294/p.v21i2.6394

\begin{abstract}
Palang Merah Indonesia is a humanitarian organization with legal status, Palang Merah Indonesia that will be discussed in this study is the Palang Merah Indonesia South Jakarta. The New Member Registration System at the Palang Merah Indonesia South Jakarta is currently using a conventional system, which still uses paper media in the recording of new members, making reports and even making members' cards, in the process of searching for data administrative members also experience difficulties, where frequent data loss or data that is already dull. So it becomes a problem in the organization. Therefore, in this study, the authors propose to create a desktop-based new member registration management information system that is expected to help the process of managing data in the organization. In this writing, the author uses the Waterfall Method for the development of the system by analyzing, doing the design phase, coding, and testing the program.
\end{abstract}

Keywords: Information System, Waterfall Method, New Member Registrasion

\section{PENDAHULUAN}

Perkembangan teknologi saat ini sudah melaju cepat ditandai dengan banyaknya masyarakat yang sudah sadar betul akan penggunaan teknologi baik website maupun aplikasi yang terdapat di smartphone masing-masing. Pemakaian media komputer pada masyarakat maupun suatu lembaga saat ini juga sudah dilakukan dengan baik, dengan tujuan membuat pekerjaan lebih mudah dan efisien bagi penggunanya. Kecepatan pengolahan data dan penyampaian informasi memiliki peran yang sangat penting bagi setiap instansi, data maupun informasi yang harus diolah tentu tidak memungkinkan dilakukan semua dengan menggunakan cara manual (Priyadi \& Lestari, 2018).

PMI adalah organisasi kemanusiaan yang berstatus badan hukum, diundangkan dengan Undang-Undang nomor 1 tahun 2018 tentang Kepalangmerahan guna menjalankan kegiatan Kepalangmerahan sesuai dengan Konvensi Jenewa Tahun 1949, dengan tujuan untuk mencegah dan meringankan penderitaan dan melindungi korban tawanan perang dan bencana, tanpa membedakan agama, bangsa, suku bangsa, warna kulit, jenis kelamin, golongan, dan Pandangan Politik. (Indonesia, n.d.)
Penerimaan anggota baru dalam suatu lembaga ataupun organisasi adalah merupakan kegiatan yang perlu dilakukan dengan cepat, tepat dan cermat. Pencatatan data anggota baru yang dilakukan tidak benar, maka akan menimbulkan masalah jika data tersebut akan digunakan dikemudian hari. Palang Merah Indonesia dalam hal pendaftaran angota baru masih menggunakan sistem yang konvensional, dimana data anggota hanya di simpan didalam sebuah kertas yang kemudian diarsipkan. Proses tersebut tentunya akan memakan waktu lama dalam pencarian data anggota jika diperlukan dan tidak menutup kemungkinan sering terjadinya kehilangan data atau data yang sudah kusam karena penyimpanan yang sudah lama dan bertumpuk, hal tersebut dapat memperlambat proses yang akan dijalankan selanjutnya. Maka dari itu berdasarkan latar belakang permasalah yang telah diuraikan diatas, permasalahan dapat disimpulkan sebagai berikut :

1. Tidak adanya media yang dapat digunakan oleh administrasi dalam mencatatat data anggota baru

2. Diperlukannya sistem pendukung yang dapat mengelola data anggota baru pada PMI Jakarta Selatan

3. Merancang sebuah media yang dapat meningkatkan pelayanan pendaftaran anggota baru pada PMI Jakarta Selatan 
Tujuan dari penelitian ini adalah merancang sebuah sistem informasi pendaftaran anggota baru yang sesuai dengan kebutuhan pengguna yang dapat mempermudah dalam proses penyimpanan, pencarian hingga pelaporan anggota baru pada PMI Jakarta Selatan. Sedangkan manfaat yang diperoleh dari hasil penelitian ini bagi objek penelitian adalah dapat menghasilkan sistem informasi pendaftaran anggota baru yang efisien dan memudahkan administrasi dalam mengelola data anggota baru setiap saat.

\section{METODOLOGI PENELITIAN}

\section{Sistem Informasi}

Sistem informasi sebagai suatu alat untuk menyajikan informasi dengan cara sedemikiam rupa sehingga bermanfaat bagi penerimanya". Tujuannya adalah untuk menyajikan informasi guna pengambilan keputusan pada perencanaan, pemrakarsaan, pengorganisasian, pengendalian kegiatan operasi subsistem dan menyajikan sinergi organisasi pada proses Menurut Alfatta dalam (Lestari \& Yani, 2019). Berikut sistem informasi berdasarkan konsep (input,processing,output).

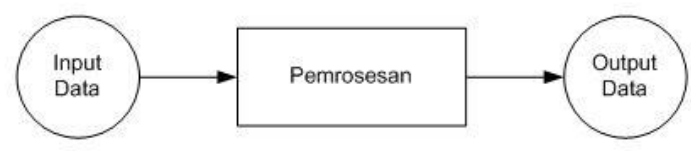

Sumber : Alfatta (2007)

Gambar 1. Konsep Sistem Informasi

\section{Model Pengembangan Sistem}

Model SDLC air terjun (waterfall) sering juga disebut model sekuensial linier (sequential linier) atau alur hidup klasik (classic life cycle). Model air terjun menyediakan pendekatan alur hidup perangkat lunak sekuensial atau terurut dimulai dari analisi, desain, pengodean, pengujian, dan tahap pendukung (support) Menurut Rosa dalam (Lestari \& Yani, 2019).

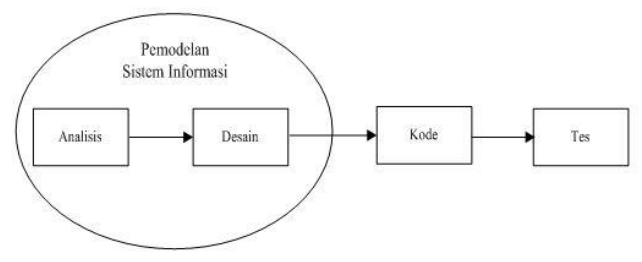

Sumber : Rosa dan Shalahuddin (2013)

Gambar 2. Ilustrasi Model Waterfall

Model sekuensial linier melingkupi aktivitasaktivitas sebagai berikut:

a. Analisa Kebutuhan Perangkat Lunak

Proses pengumpulan kebutuhan dilakukan secara intensif untuk menspesifikasikan kebutuhan perangkat lunak agar dapat dipahami perangkat lunak seperti apa yang dibutuhkan oleh user. Spesifikasi kebutuhan perangkat lunak pada tahap ini perlu untuk didokumentasikan.

b. Desain

Desain perangkat lunak adalah proses multi langkah yang fokus pada desain pembuatan program perangkat lunak termasuk struktur data, arsitek perangkat lunak, presentasi antar muka, dan prosedur pengkodean. Tahap ini mentranslasi ke reresentasi desain agar dapat diimplementasikan menjadi program pada tahap selanjutnya. Desain perangkat lunak yang dihasilkan pada tahap ini juga perlu di dokmentasikan.

c. Pembuatan Kode Program

Desain harus ditranslasikan ke dalam program perangkat lunak. Hasil dari tahap ini adalah program komputer sesuai dengan desain yang telah dibuat pada tahap desain.

d. Pengujian

Pengujian fokus pada perangkat lunak secara dari segi logic dan fungsional dan memastikan bahwa semua bagian sudah diuji. Hal ini dilakukan untuk meminimalisir kesalahan (error) dan memastikan keluaran yang dihasilkan sesuai dengan yang diinginkan.

e. Pendukung (support)atau pemeliharaan (maintenance)

Tidak menutup kemungkinan sebuah perangkat lunak mengalamai perubahan ketika sudah dikirim ke user. Perubahan bisa terjadi karena adanya kesalahan yang muncul dan tidak terdeteksi saat pengujian atau perangkat lunak harus beradaptasi dengan lingkungan baru. Tahap pendukung atau pemeliharaan dapat mengulangi proses pengembangan mulai dari analisis spesifikasi untuk perubahan perangkat lunak yang sudah ada, tetapi tidak untuk membuat perangkat lunak baru.

\section{Entity Relationship Diagram}

Entity Relationship Diagram(ERD) adalah suatu model jarinagan yang menggunakan susunan data yang disimpan dalam sistem informasi secara abstrak Menurut Amrin dan Murni dalam (Priyadi \& Lestari, 2018).

ERD merupakan suatu model yang diguanakan untuk menjelaskan hubungan antar data dalam basis data berdasarklan objek-objek dasar data yang mempunyai hubungan antar relasi. ERD berfungsi untuk memodelkan struktur data dan hubungan antar data, untuk menggambarkannya diguanakan beberapa notasi dan simbol. Pada dasarnya ada tiga simbol yang digunakan, yaitu:

a. Entity

Entity merupakan objek yang mewakili sesuatu yang nyata dan dapat dibedakan dari sesuatu yang lain. Entity juga yaitu sesuatu yang dapat dibedakan dalam dunia nyata di mana informasi yang berkaitan dengannya dikumpulkan. Simbol dari entity ini biasanya digambarkan dengan persegi panjang. b. Relationship 
Relationship adalah hubungan yang terjadi antara satu entity atau lebih entity. Relationship tidak memiliki keberadaan fisik, kecuali yang mewarisi hubungan antara entity tersebut. Simbol yang digunakan adalah bentuk belah ketupat, diamond atau rectangle.

c. Atribute

Atribute adalah karakteristik dari entity atau relationship yang menyediakan penjelasan detail tentang atau relationship tersebut. Atribut value (nilai atribute) adalah suatu data aktual atau informasi yang disimpan di suatu atribute di dalam suatu entity atau relationship.

Terdapat dua jenis atribute, yaitu Identifier (key), untuk menentukan suatu entity secara unik. Dan Descriptor (nonkey atribute), untuk menentukan karakteristik dari suatu entity yang tidak unik.

\section{Unified Modeling Language (UML)}

The Unified Modeling Language (UML) adalah sebuah kumpulan notasi grafis, yang didukung dengan single meta-model, itu dapat membantu kita menggambarkan dan merancang sebuah sistem software, khususnya sistem software yang dibuat menggunakan teknik object-oriented (OO) menurut Fowler dalam (Lestari \& Yani, 2019).

Seperti bahasa-bahasa lainnya, UML mendefinisikan notasi dan syntax/semantik. notasi UML merupakan sekumpulan bentuk khusus untuk menggambarkan berbagai diagram peranti lunak. Setiap bentuk memiliki makna tertentu, dan UML syntax mendefinisikan bagaimana bentuk-bentuk tersebut dapat dikombinasikan. Notasi UML terutama diturunkan dari 3 notasi yang telah ada sebelumnya : Grady Booch OOD (Object Oriented Design), Jim Rumbaugh OMT (Object Modelling Technique), dan Ivar Jacobson OOSE (Object Oriented Software Enginering).

a. Use Case Diagram

Use Case Diagram merupakan Pemodelan untuk kelakuan (behavior) sistem informasi yang akan dibuat. Use Case digunakan untuk mengetahui fungsi apa saja yang ada di dalam sistem informasi dan siapa saja yang berhak menggunakan fungsifungsi tersebut. Terdiri dari Actor, Use Case, Association Relationship, Directed Association Relationship.

b. Activity Diagram

Activity Diagram menggambarkan workflow (aliran kerja) atau aktivitas dari sebuah sistem atau proses bisnis. Terdiri dari Activity, Action, Intional Node, Activity Final Node, Decisiton, Line Contruction

c. Class Diagram

Merupakan hubungan antar kelas dan penjelasan detail tiap-tiap kelas di dalam model desain dari suatu sistem, juga memperlihatkan aturan-aturan dan tanggung jawab entitas yang menenttukan perilaku sistem. Terdiri dari Generalitation, Class, Colaboration, Realization, Dependency, Associaton. d. Sequence Diagram

Sequence Diagram menggambarkan kelakuan objek pada use case dengan mendeskripsikan waktu hidup objek dan pesan yang dikirim dan diterima antar objek. Terdiri dari Actor, Entity Class, Boundary Class, Control Class, A Focus of Control \& A Life Line, A Message.

\section{Proses Bisnis Sistem Berjalan}

Seorang calon anggota datang langsung ke PMI untuk melakukan pendaftaran sebagai anggota kemudian admin menjelaskan mengenai hal-hal yang ada di PMI dan memberikan formulir pendaftaran kosong kepada calon anggota, calon anggota kemudian menerima formulir kosong dan mengisi data formulir perndaftaran tersebut dengan lengkap dan benar menyertai lampiran-lampiran yang dibutuhkan. Setelah diisi, formulir dikembalikan kepada bagian admin. Kemudian admin akan memeriksa dan mengesahkan formulir untuk diarsipkan. Setiap bulannya admin pendaftaran akan membuat laporan pendaftaran anggota baru yang kemudian akan diserahkan kepada pembina untuk diperiksa dan di tandatangani.

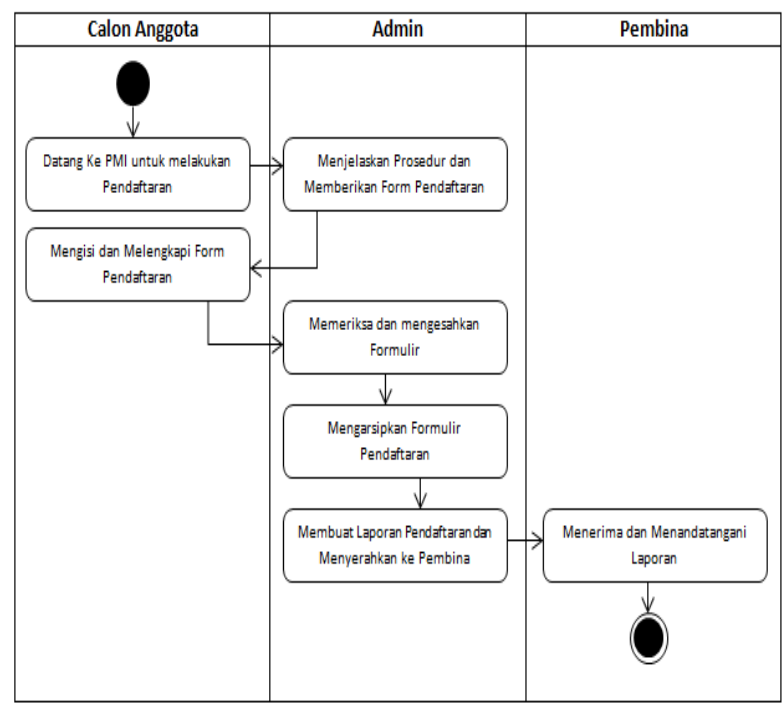

Gambar 3. Proses Sistem Berjalan

\section{Permasalahan dan Pemecahan Masalah}

Permasalahan yang ada pada Palang Merah Indonesia Jakarta Selatan adalah Pengarsipan file anggota masih manual sehingga penyimpanan berkas sering terjadi kehilangan. Pencarian data anggota sulit untuk ditemukan sehingga memerlukan waktu dan yang cukup lama menacarinya kembali. Proses penyeleksian spesialisasi masih rumit. Maka dari itu pemecahan masalahnya dapat diuraikan seperti Melakukan pengarsipan file anggota tidak hanya disimpan kedalam lemari atau loker akan tetapi juga harus diinput atau disimpan juga kedalam komputer agar mempunyai salinan dari file tersebut. Pengarsipan data nggota seharusnya disimpan sesuai dengan tahun pendafatran para anggota atau angkatan pendaftaran. Membuat pendataan ulang terhadap para anggota agar bisa dibuat daftar baru lagi untuk penyimpanan data spesialisasi. 


\section{HASIL DAN PEMBAHASAN}

\section{Analisa Kebutuhan Sistem}

Menganalisa kebutuhan dari sistem yang akan dikembangkan adalah salah satu tahapan penting yang harus dilakukan dalam suatu penelitian. Tujuannya adalah agar sistem yang dikembangkan dapat sesuai dengan kebutuhan pengguna sistem nantinya. Berikut beberapa tahapan dalam pengembangan sistem pendaftaran anggota baru pada Palang Merah Indonesia Jakarta Selatan.

a. Kebutuhan Admin : Admin dapat melakukan login, Mengelola Data Admin, Mengelola Data Anggota, Mengelola Pendaftaran Anggota, Mengelola Spesialisasi, Mengelola Laporan, Mengelola Kartu Anggota

b. Kebutuhan Pembina : Pembina dapat melakukan Login, Mencetak Kartu Anggota dan Mencetak Laporan

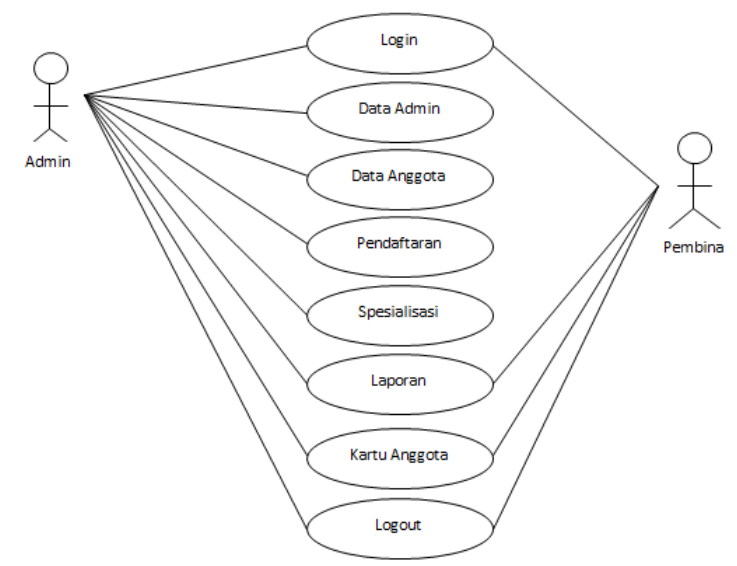

Gambar 4. Use Case Diagram Pendaftaran Anggota Baru

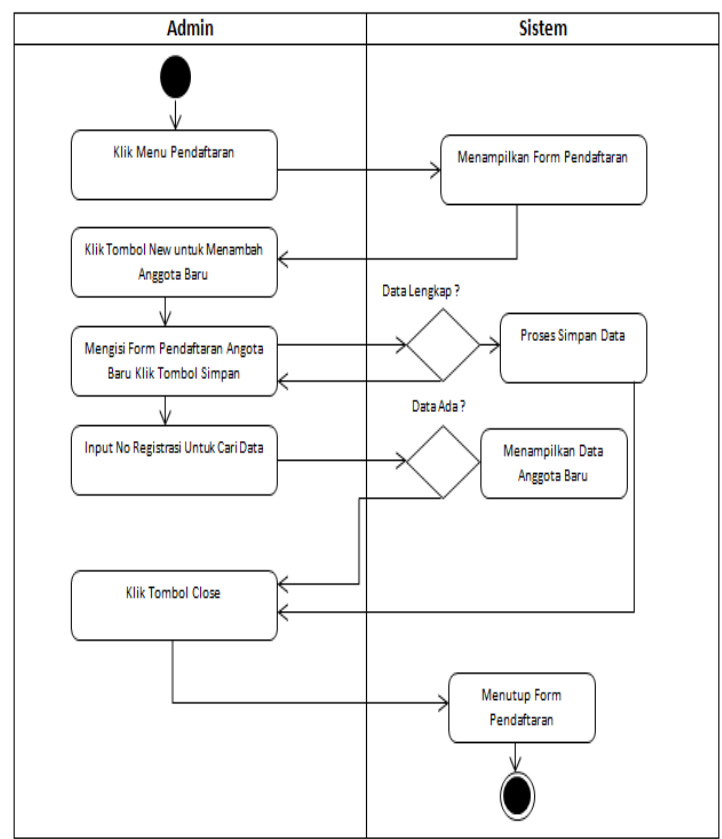

Gambar 5. Activity Diagram Pendaftaran Anggota Baru
Gambaran dari Entity Relationship Diagram pada Pendaftaran Anggota Baru di Palang merah Indonesia Jakarta Selatan bisa dilihat di Gambar 6.

Gambaran dari Class Diagram dapat dilihat pada Gambar 7.

Gambaran Sequence Diagram dapat dilihat pada Gambar 8.

User Interface dari Pendaftaran Anggota Baru dapat dilihat di gambar 9.

\section{KESIMPULAN}

Berdasarkan uraian yang telah dipaparkan, serta hasil dari pengamatan dari sistem usulan pada sistem informasi pendaftaran anggota baru pada Palang Meranh Indonesia Jakarta maka dapat ditarik kesimpulan bahwa sistem informasi pendaftaran ini dapat membantu dalam mengelola data calon anggota, memudahkan dalam proses pencarian data anggota, data spesialisasi, mengurangi terjadinya kehilangan data karena penyimpanannya yang sudah menggunakan database, dan membantu dalam penyusunan laporan lebih cepat dan tepat.

Untuk pengembangan lebih lanjut mengenai sistem informasi pendaftaran anggota PMI ini, maka perlu adanya pengembangan program pendaftaran menggunakan media web, agar ketika anggota datang, maka bisa langsung di lihat oleh admin tanpa perlu melakukan pendaftaran ditempat.

\section{REFERENSI}

Alfatta, H. (2007). Analisis dan Perancangan System Informasi untuk Keunggulan Perusahaan dan Organisasi Kelas Dunia. Yogyakarta: ANDI.

Fowler, M. (2005). UML Distilled: Panduan Singkat Bahasa Pemodelan Objek Standar (3rd ed.). Yogyakarta: Andi Offset.

Indonesia, P. M. (n.d.). Sejarah Palang Merah Indonesia. Retrieved from http://pmi.or.id/

Lestari, E. W., \& Yani, N. (2019). Perancangan Pembelajaran Daring SMK PGRI 1 Jakarta, XXI(1), 9-16. https://doi.org/10.31294/p.v20i2

Priyadi, D. A., \& Lestari, E. W. (2018). Perancangan Sistem Informasi Pelayanan Surat Menyurat Pada Kantor Desa Tanjungsari Kutowinangun Kebumen Berbasis Desktop, IV(2). https://doi.org/10.31294/jtk.v4i2.3444

Rosa, S. (2013). Rekayasa Perangkat Lunak. Bandung: Informatika. 


\section{PROFIL PENULIS}

Endah Wiji Lestari, lahir di Jakarta, tanggal 10 September 1989. Telah menjalani pendidikan di D3 Universitas Bina Sarana Informatika Program Studi Manajemen Informatika dan menyelesaikannya pada tahun 2011, kemudian pada tahun 2012 melanjutkan ke jenjang pendidikan S1 di Sekolah Tinggi Manajemen Informatika Nusa Mandiri Jakarta program studi Sistem Informasi dan menyelesaikannya pada tahun 2013. Pada tahun
2013 melanjutkan ke jenjang pendidikan S2 di Program Pasca Sarjana Universitas Budi Luhur Jakarta, Program studi Magister Ilmu Komputer dan menyelesaikannya pada tahun 2015 .

Nanda Yustie Mirchandini, lahir di Jakarta 21 April 2019. Telah menjalani pendidikan di D3 Universitas Bina Sarana Informatika Program Studi Sistem Informasi dan menyelesaikannya pada tahun 2017.

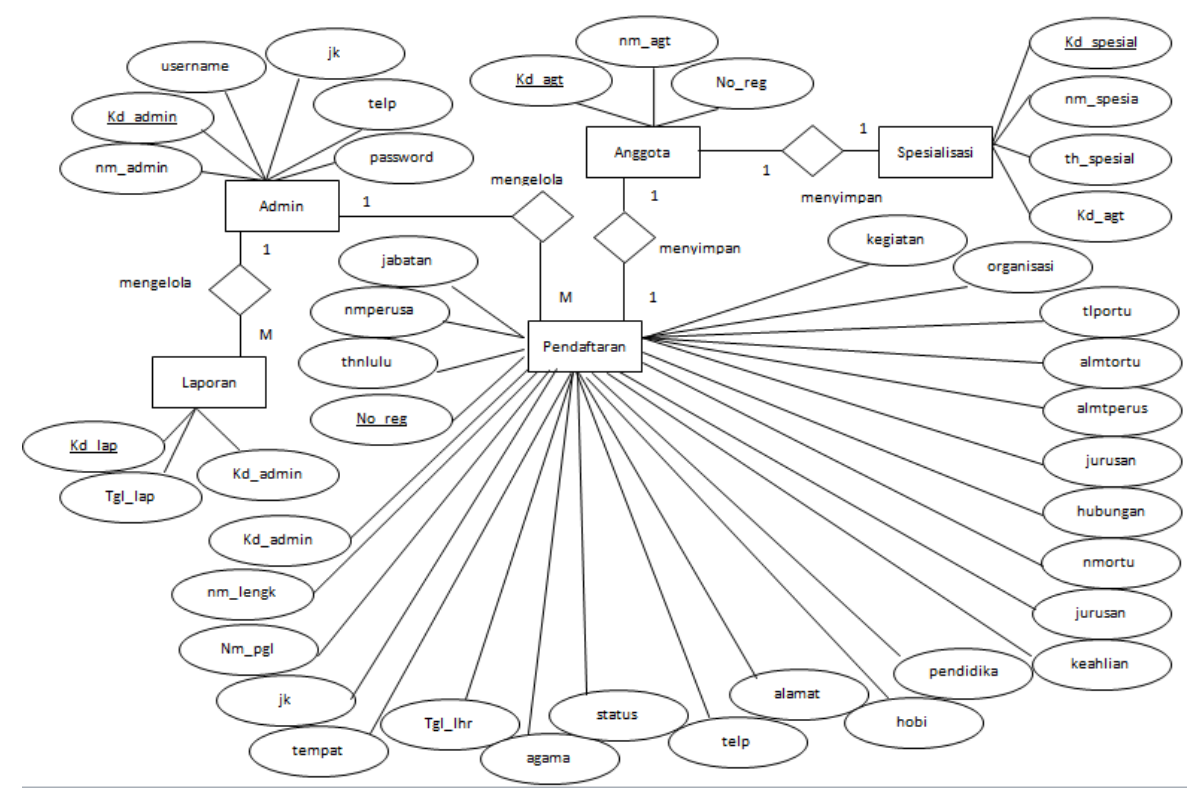

Gambar 6. Entity Relationship Diagram

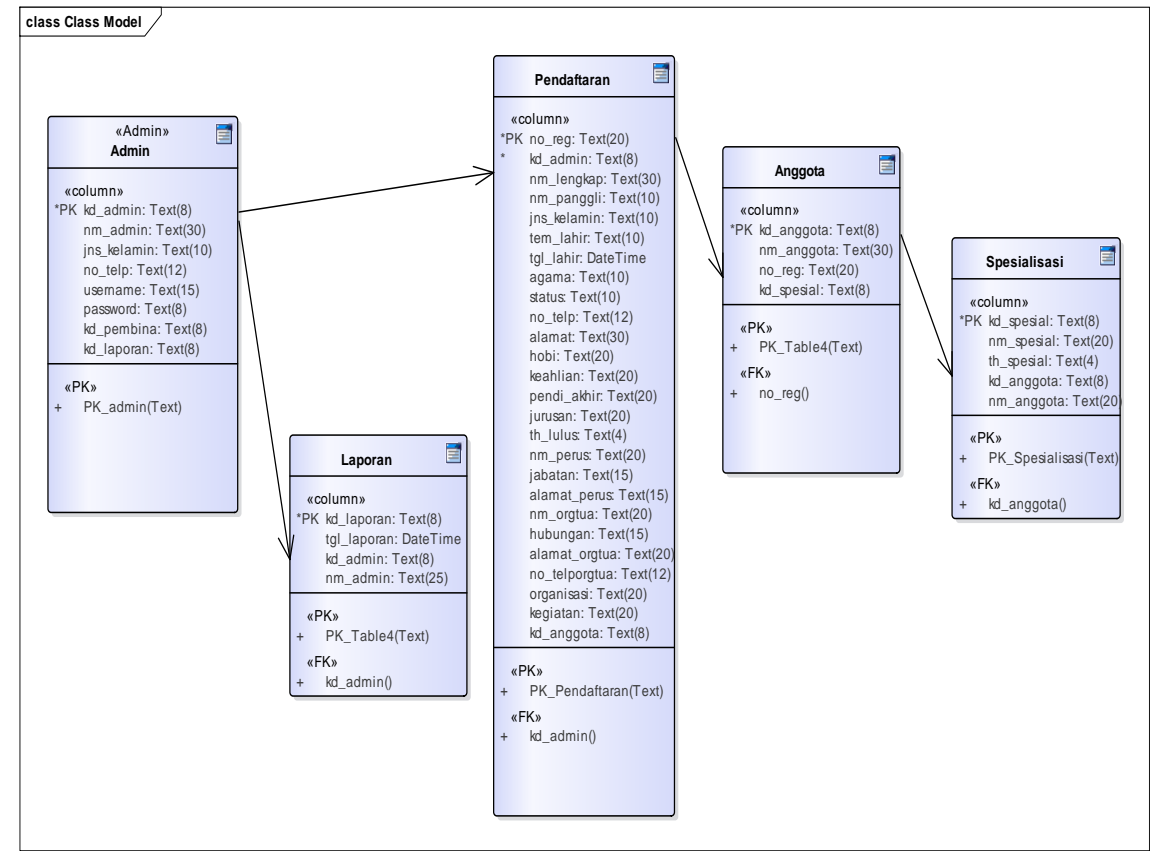


Gambar 7. Class Diagram

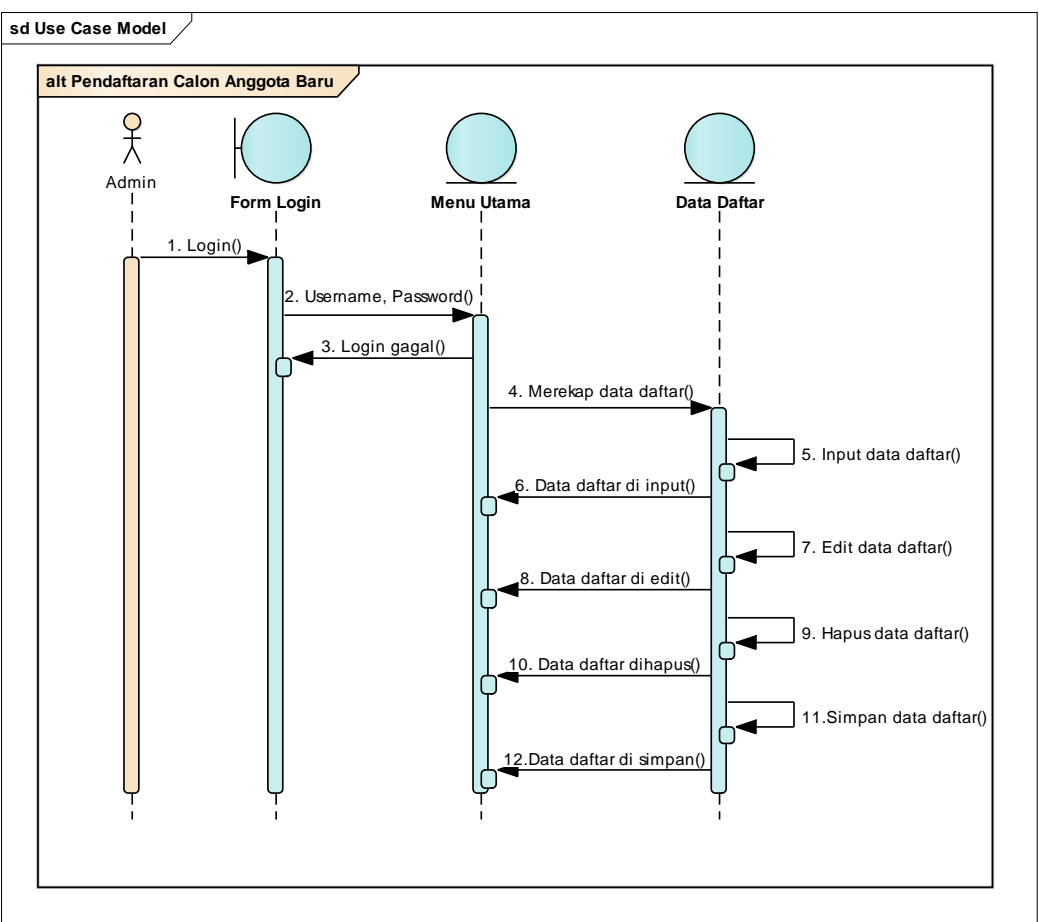

Gambar 8. Sequence Diagram Form Pendaftaran

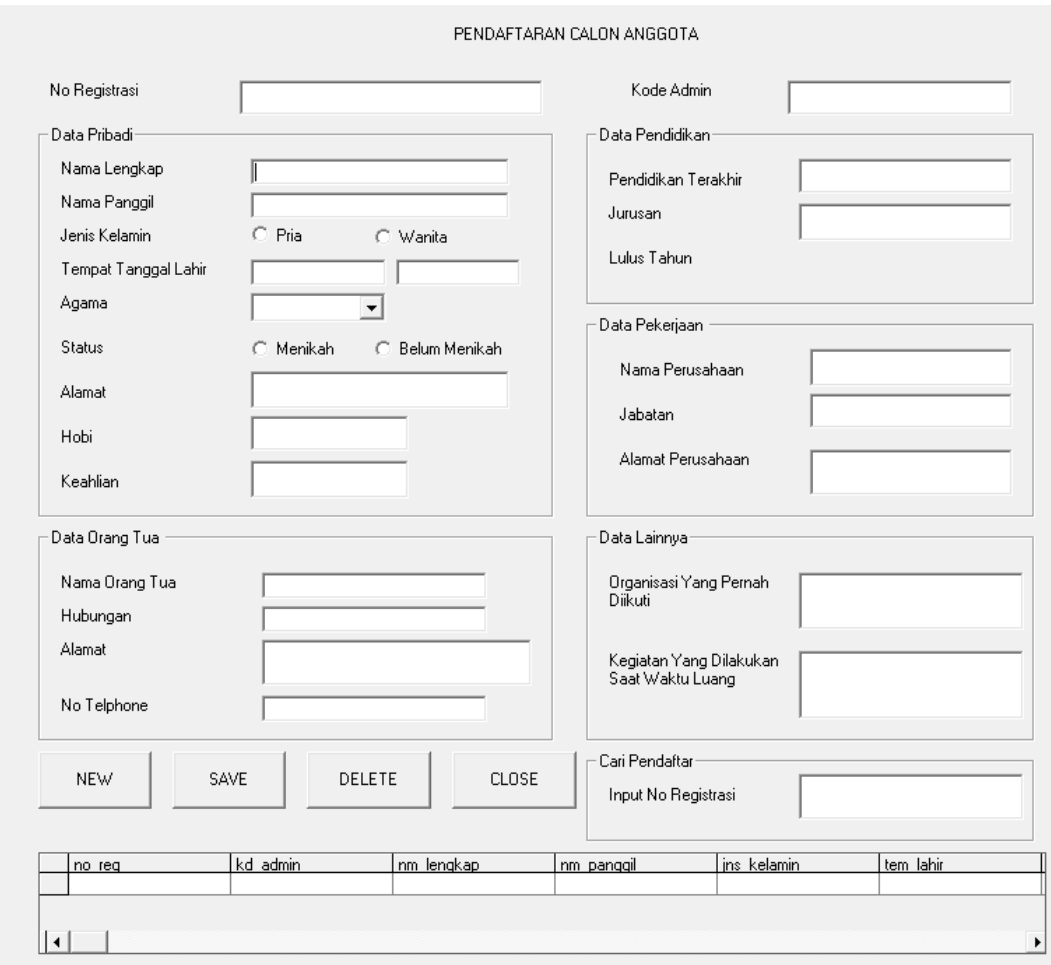

Gambar 9. User Interface Form Pendaftaran 